\title{
Utilisation of Sentinel-1 SAR Imagery for Oil Spill Mapping: A Case Study of Balikpapan Bay Oil Spill
}

\author{
Ratna Prastyani, Abdul Basith \\ Departemen Teknik Geodesi, Universitas Gadjah Mada, INDONESIA
}

\section{Article History:}

Received 4 September 2018

Received in revised form 21 September 2018

Accepted 21 September 2018

Available online 25 September 2018

Keywords:

oil spill, Balikpapan bay, Sentinel-1, SNAP,

marine ecosystem

Corresponding Author:
Ratna Prastyani
Email: ratna.prastyani@mail.ugm.ac.id

Corresponding Author:

Email: ratna.prastyani@mail.ugm.ac.id

\begin{abstract}
Oil spill is a great threat for marine ecosystem. Oil discharge has become a public concern in all over the world with the increase of marine traffics. Indonesian government has declared state of emergency over oil spill which devastated Balikpapan bay in March 2018. The deadly oil spill impacts marine ecosystem as well as the communities. This study aims to map the oil spill over Balikpapan bay by utilising SAR imagery of Sentinel-1. Automatic and semiautomatic approaches are presented in this study to detect the oil spill. Oil spill is automatically detected using Oil Spill Detection toolbox of Sentinel Application Platform (SNAP). Furthermore, semi-automatic method is also demonstrated by utilising pre and post-oil spill SAR imageries. Our experiment shows that semiautomatic method has better performance than automatic detection by SNAP. Nevertheless, both approaches are useful to map oil spill in term of time and cost effectiveness.
\end{abstract}

(C) Author(s) 2018. This is an open access article under the Creative Commons Attribution-ShareAlike 4.0 International License (CC BY-SA 4.0).

\section{Introduction}

Oil spill poses a serious threat and damage to marine ecosystem. Oil pollution might truly devastate marine environment and the communities along the coastline. From environment point of view, oil spill does not only affect the ecosystem right after the occurrence, but it also has long-term marine environmental effect that might take extremely long time for the environment itself to recover (Kingston, 2002).

Oil spill in Balikpapan seaport is one of the worst tragedies in the history of maritime pollution in Indonesia. Oil spill was recorded on 29 March 2018 and authorities confirmed that it was due to cracked underwater pipeline of PERTAMINA. PERTAMINA, state-owned oil and gas company, claimed to take a full responsibility for the oil spill. The oil spill ignited flames a few kilometres high and caused the death of five fishermen. In addition, the oil spill also caused respiratory problem in the city and poisoned marine life. Fig.1.1 shows some devastations caused by the deadly oil spill. Indonesian government has also declared state of emergency over the tragedy. With all the devastations that oil spill caused, oil spill information such as its spreading over the water is truly important that supports government decision making for oil spill cleaning, rescue and mitigation operation.

Oil spill detection using satellite-based imagery provides opportunities to effectively map oil pollution in large scale. Satellite-based imageries of both active and passive sensor are frequently used to detect, map and monitor oil spill (Kolokoussis, 2018; Fiscella et al., 2000; Solberg et al., 2007; Bayramov et al., 2018; Brekke and Solberg, 2005). However, active-remote sensing data such as Synthetic Aperture Radar (SAR) imagery plays an important role in oil spill detection for its all-day-andnight sensing capability. SAR imagery can record and capture the image of the oil spill on Earth in all type of weather as the microwave penetrates through cloud, fog, or even snow. In addition, the revisit time property of satellite is also considered to carry out a multitemporal monitoring of oil spill (Liu et al., 2016). However, one of the major challenges to map oil spill using SAR imagery is to distinguish oil spill over water body and look-alikes. Look-alikes appear as darker area on SAR imagery in which darker area also represents oil slick. Look-alikes 
includes natural slick such as ice, internal waves, shear zone, etc. (Espedal, 1999).
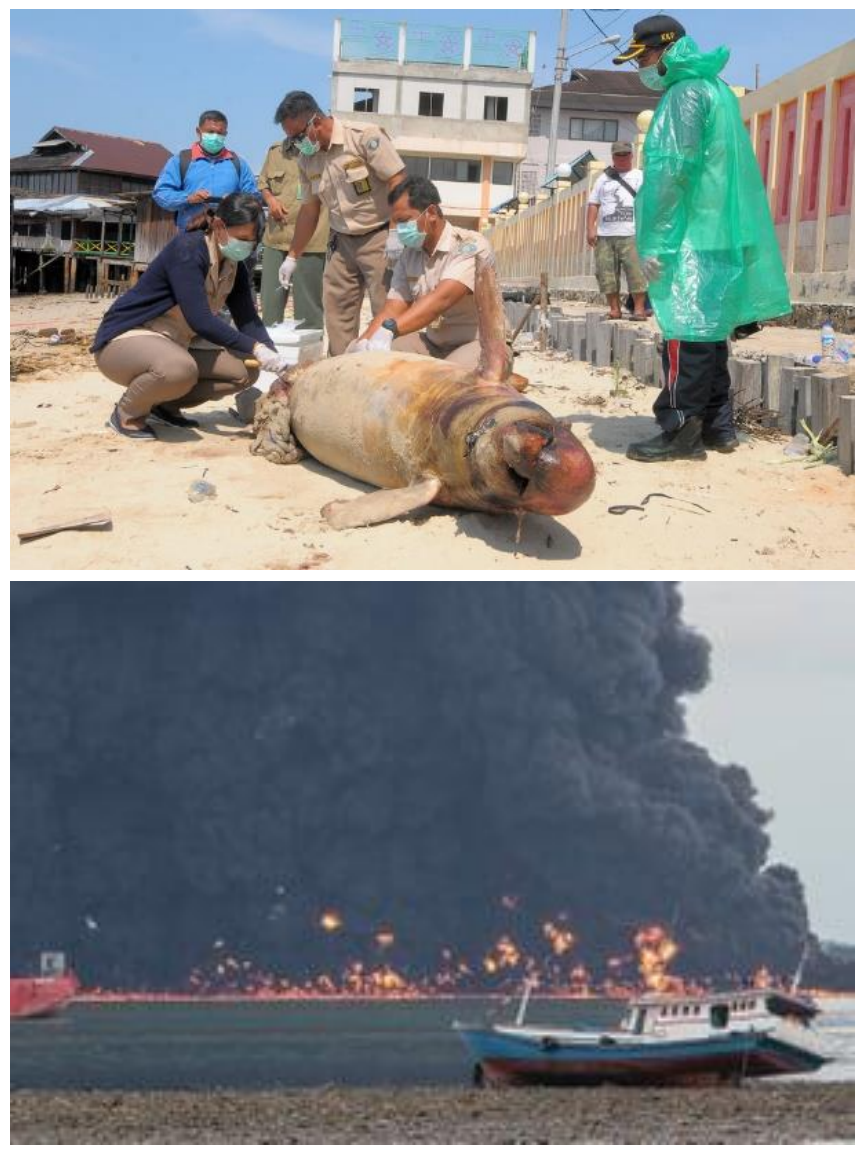

Fig.1.1 Oil pollution poisoned an Irrawaddy dolphin (top) and the flame ignited due to oil spill (bottom)

(Source: www.theguardian.com)

Sentinel-1 is a satellite with active sensor that is launched into orbit in 2014. One of its main mission is related to ocean, sea and sea-ice monitoring such as seaice monitoring, oil spill monitoring, maritime surveillance services and wave monitoring (Potin et al., 2012). With revisit time of 12 days, Sentinel-1 is essential for ocean monitoring application. In some cases, Sentinel-1 data can be accessed nearly real time or less than in 10 minutes with no cost.

The objective of this study is to detect and map oil spill in Balikpapan Bay using SAR imagery of Sentinel-1. Fully automatic and semi-automatic approaches are presented to compare both methods in oil spill mapping. This experiment utilises Sentinel-1 SAR imageries and Sentinel Application Platform (SNAP). SNAP is an open-source software for Sentinel data processing which can be downloaded for free on.

\section{Datasets and Methodology}

\subsection{Datasets}

In this experiment, Sentinel-1 imagery is used to detect and map oil spill over Balikpapan waters. Sentinel-1 imageries include the Ground Range Detected (GRD) product which were recorded by Sentinel-1A platform. For semi-automatic approach, pre-oil spill imagery acquired on 8 March 2018 and post-oil spill imagery acquired on 1 April 2018 are used, while in automatic oil spill detection process, post-oil spill imagery acquired on 1 April 2018 is sufficient to extract oil spill spread. Both datasets were acquired in Vertical-Vertical (VV) and Vertical-Horizontal $(\mathrm{VH})$ polarisation. However, imagery with VV polarisation is more effective in detecting oil spill since the oil spill is more clearly observed and distinguished (Fig.1.2).

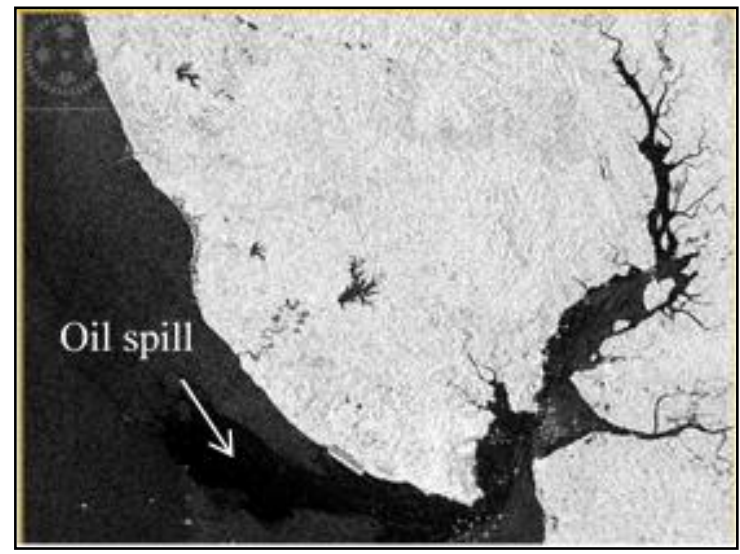

Fig.1.2 Oil spill in Sentinel-1 imagery with VV polarisation appears as darker area.

\subsection{Methodology}

2.2.1 Data Pre-processing

Data pre-processing includes radiometric and geometric correction. Radiometric correction refers to speckle filtering. SAR imagery basically inheres 'salt and pepper' appearance which degrades the quality of imagery (Misra and Balaji, 2017). Speckle filtering is made to eliminate those speckle errors on imagery and to increase its quality. Speckle filtering of 'Lee Sigma' with kernel size of $7 \times 7$ is used with SNAP toolbox.

We also geometrically correct the imagery by performing Ellipsoid Correction-Geolocation Grid using SNAP. We do not perform terrain correction because our main concern is about only the oil spill over water and not the quality of terrain over land. Therefore, ellipsoid correction is sufficient to ensure that the geometric of imagery closely represents the real world.

\subsubsection{Semi-automatic approach}

In this proposed semi-automatic detection method, two imageries (pre and post-oil spill) are required to 
determine oil spread over the water. The two imageries were recorded before and after oil spill. We recognise the phenomenon of progressive decrease of backscatter energy or brightness from near to far range in Wide Swath SAR imageries which in fact might affect object classifications on SAR imageries (Singha, 2013; Topouzelis et al., 2016). However, based on our observation that the decrease of brightness from near to far range does not appear to be significant decrease. Therefore, radiometric normalisation of SAR imageries is not desirable in this experiment. The basic principle of this method is thresholding oil spill area. Oil spill dampens the water surface and creates dark area in SAR imagery (Misra and Balaji, 2017). In order to extract the dark area which represents oil spill, band maths called difference is used to obtain dark pixel which does not exist in pre-oil spill imagery but is clearly shown after oil spill. Pixels with oil spill contains lower value than pixels which are free from oil spill. However, those lower values vary in every pixel. By comparing and differencing the pixel value two imageries of pre and post-oil spill, a more comprehensive thresholding can be determined and performed to detect oil spill. Apart from data pre-processing, this semiautomatic approach includes image cropping, land-sea masking, stacking and differencing two imageries based on determined threshold. Land-sea masking is carried out to mask out the land since our main concern is the oil spill over water body or the sea. Moreover, stacking is required in order to perform band math which involves two imageries. The process of semi-automatic oil spill detection is performed with Batch Processing toolbox which is shown in Fig.2.1.

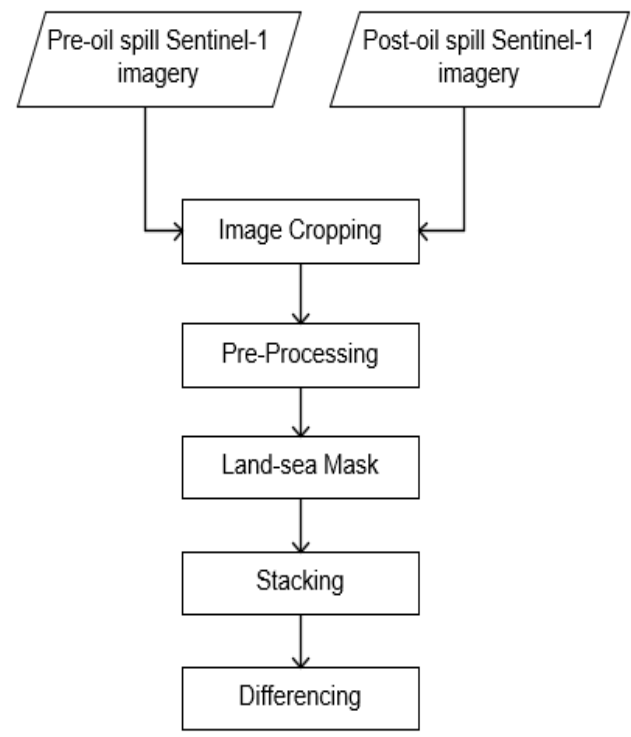

Fig. 2.1 Semi-automatic process for oil spill mapping using Graph Builder in SNAP

\subsubsection{Automatic approach}

SNAP provides a fully automatic oil spill mapping called Oil Spill Detection. This is one of the tools which is provided under SAR Ocean Application of SNAP. The process is performed automatically by algorithm. The basic principle of Oil Spill Detection by SNAP is to identify dark pixels over the sea. The algorithm includes dark pixels identification using adaptive thresholding, clustering and discriminating dark pixels based on cluster dimension with user preference of cluster size input (Misra and Balaji, 2017).

Adaptive threshold algorithm is done by estimating local mean backscatter level in determined window which depends on the Background Window Size parameter. The identified dark pixels are pixels whose value is lower $k$ decibels than the estimated local mean backscatter, in other words the $k$ decibels is determined by user or left as default in the Threshold Shift parameter. The final process of the algorithm is to cluster and discriminate dark pixels based on the dimension of the cluster and user selected minimum cluster size. Automatic oil spill mapping using this algorithm is carried out with default parameters which are background window size of 61 , threshold shift of 2.0 (in $\mathrm{dB}$ ) and minimum cluster size of 0.1 square $\mathrm{km}$. The default parameters are applied to evaluate the algorithm in detecting oil spill in this particular case.

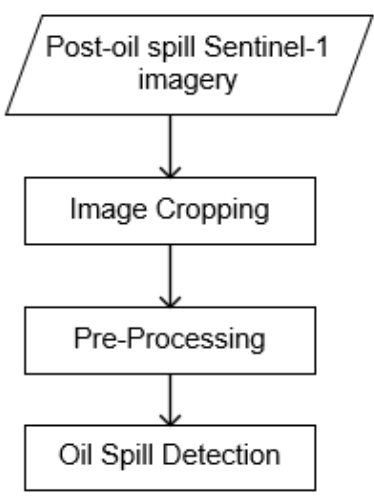

Fig. 2.2 Automatıc oll spıII mappıng using Oil Spill Detection in SNAP

\section{Results and Discussion}

\subsection{Semi-automatic approach}

In this approach, several processes are made to map oil spill over Balikpapan bay. Pixel values in post-oil spill imagery are lower than the pixels on pre-oil spill imagery. Profiling across oil spill and the clear water are made to see the impact of oil slick which dampens the water. 


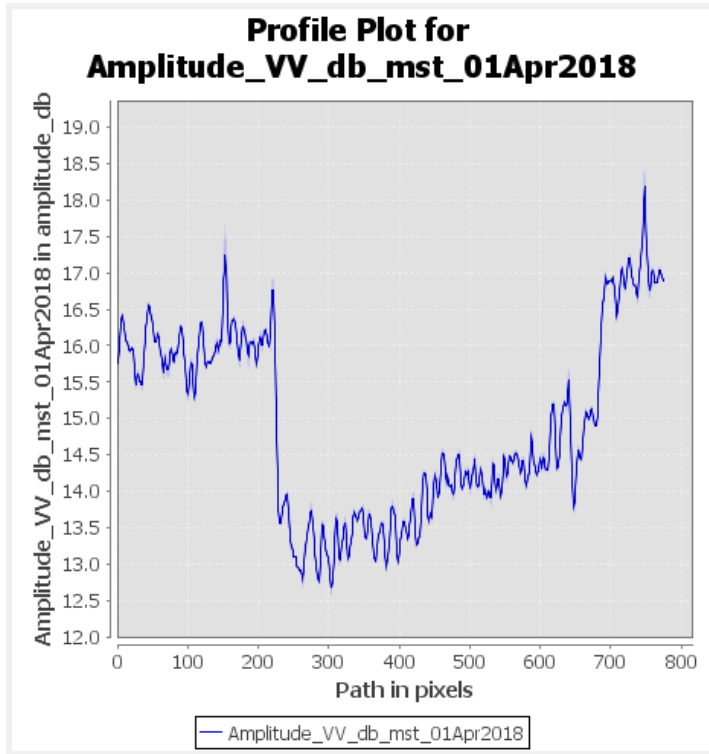

Fig.3.1 Pixel profiling across oil slick and clear water

Generally, water which has been polluted by oil slick would have lower pixel values or appear to be darker. Based on the graph of Fig.3.1, we can see that pixels with oil spill have lower value for about $3 \mathrm{~dB}$ than the surrounding clear water. Therefore, thresholding of $3 \mathrm{~dB}$ or slightly lower than $3 \mathrm{~dB}$ is used to extract pixels with oil spill. Fig.3.2 shows the result of oil spill mapping using our first approach.

Based on the results, our proposed method has successfully detected oil spill. As mentioned before, many look-alikes pixels are also detected as oil spill creating false detection. In addition, waves along coastline are mainly detected as oil slick. However, the overall result allows us to map the oil spill.

\subsection{Automatic approach}

Here, Oil Spill Detection by SNAP is carried out as a fully automatic approach. The oil spill detection is done using default parameters (Section 3.2). However, with the default parameters, the algorithm does not successfully detect oil spill (Fig.3.2). Pixels detected as oil spill are likely represents a few look-alikes which can barely be seen across the entire study area. This method with default parameters is quite poor in detecting oil spill since only a few pixels are detected. The failure of oil spill detection by automatic approach in this experiment is mainly due to the parameter set for algorithm. Background Window Size in which the local mean backscatter is estimated is too small. This causes the estimated local mean backscatter is quite similar to the individual pixel on the image. Furthermore, Threshold Shift parameter of 2 decibel is not sufficient either to discriminate dark pixels. This experiment of automatic oil spill detection provided by SNAP with default parameters is not effective in detecting oil slick and can not be used to support decision-making pertaining to rescue and cleaning operation.
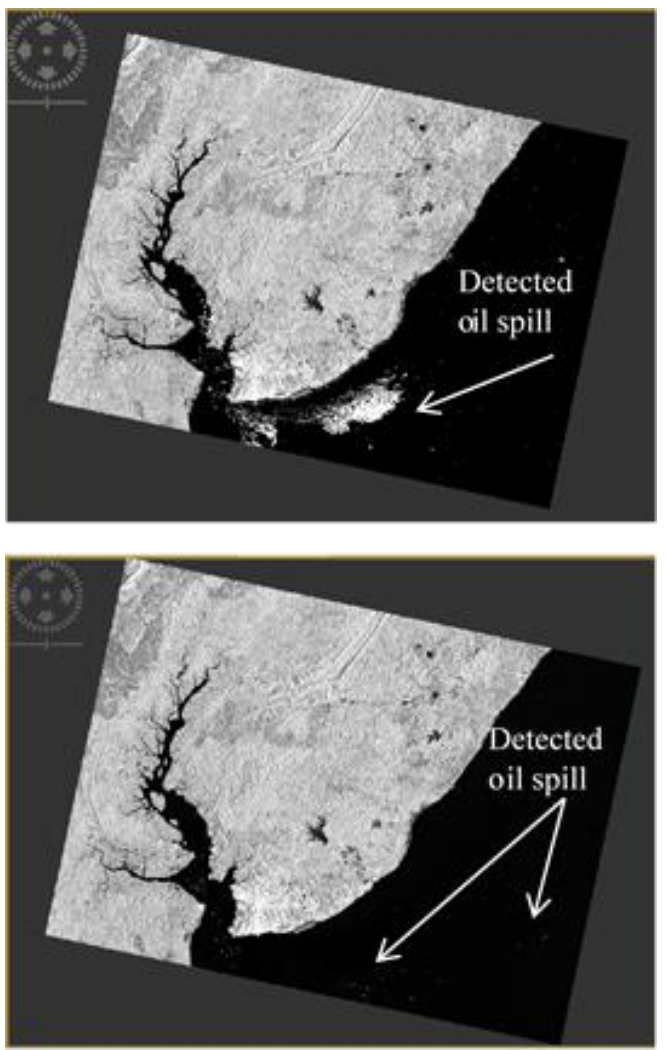

Fig.3.2 Oil spill detection using semi-automatic approach (top) and automatic approach (bottom).

In addition, it is possible to increase the quality of Oil Spill Detection result by using appropriate parameters in future experiments. However, it might be more timeconsuming process than the first approach and require more advanced hardware specification for data processing.

\section{Conclusion}

This study has presented two approaches for oil spill mapping in Balikpapan Bay. The first method of semiautomatic detection has mapped oil spill spread over Balikpapan water quite well. On the contrary, automatic approach using Oil Spill Detection by SNAP with the default parameters has not successfully detected oil spill in Sentinel-1 imagery. However, both approaches are useful for oil spill mapping in term of its cost and time effectiveness. It is also worth mentioning that oil spill mapping using SAR imageries is quite challenging due to phenomenon called look-alikes which causes false detection. Fieldwork is required to validate whether or not the oil spill in certain places has taken place. 


\section{Conflicts of Interest Statement}

The authors declare no competing interest in this article.

\section{References}

Bayramov, Emil, Martin Kada, and Manfred Buchroithner. 2018. "Monitoring Oil Spill Hotspots, Contamination Probability Modelling and Assessment of Coastal Impacts in the Caspian Sea Using SENTINEL-1, LANDSAT-8, RADARSAT, ENVISAT and ERS Satellite Sensors." Journal of Operational Oceanography 11 (1). Taylor \& Francis:27-43. https://doi.org/10.1080/1755876X.2018.1438343.

Brekke, Camilla, and Anne H.S. Solberg. 2005. "Oil Spill Detection by Satellite Remote Sensing." Remote Sensing of Environment 95 (1):1-13. https://doi.org/10.1016/j.rse.2004.11.015.

Espedal, H. (1999). Detection of oil spill and natural film in the marine environment by spaceborne SAR. In Geoscience and Remote Sensing Symposium, 1999. IGARSS'99 Proceedings. IEEE 1999 International (Vol. 3, pp. 1478-1480). http://dx.doi. org/10.1109/IGARSS.1999.771993.

Fiscella, B., A. Giancaspro, F. Nirchio, P. Pavese, and P. Trivero. 2000. "Oil Spill Detection Using Marine SAR Images." International Journal of Remote Sensing 21 (18):3561-66. https://doi.org/10.1080/014311600750037589.

Kingston, Paul F. 2002. "Long-Term Environmental Impact of Oil Spills." Spill Science and Technology Bulletin https://doi.org/10.1016/S1353-2561(02)00051-8.

Kolokoussis, Polychronis. 2018. "Oil Spill Detection and Mapping Using Sentinel 2 Imagery." Journal of Marine Science and Engineering (1):4.https://doi.org/10.3390/jmse6010004.

Liu, Sicong, Mingmin Chi, Yangxiu Zou, and Ali Samat. 2016. "A Multitemporal Change Detection Solution To Oil Spill Monitoring." IEEE IGARSS, 2016.

Misra, A., and R. Balaji. 2017. "Simple Approaches to Oil Spill Detection Using Sentinel Application Platform (SNAP)-Ocean Application Tools and Texture Analysis: A Comparative Study." Journal of the Indian Society of Remote Sensing 45 (6). Springer India, https://doi.org/10.1007/s12524-016-0658-2.

Potin, Pierre, Pier Bargellini, Henri Laur, Betlem Rosich, and Siegfried Schmuck. 2012. "Sentinel-1 Mission Operations Concept." 2012 IEEE International Geoscience and Remote Sensing Symposium. IEEE, $1745-48$. https://doi.org/10.1109/IGARSS.2012.6351183

Singha, Suman, Konstantinos Topouzelis, Michele Vespe, and Olaf Trieschmann. 2013. "Radiometric Normalization on Sar Images for Oil Spill Detection" https://www.researchgate.net/publication/262241 886_Radiometric_normalization_on_SAR_images_for_ oil_spill_detection.

Solberg, Anne H S, Camilla Brekke, and Per Ove Husøy. 2007. "Oil Spill Detection in Radarsat and Envisat SAR Images." IEEE Transactions on Geoscience and Remote Sensing 45 (3):746-54. https://doi.org/10.1109/TGRS.2006.887019.

Topouzelis, Konstantinos, and Suman Singha. 2016. "Incidence Angle Normalization of Wide Swath SAR Data for Oceanographic Applications." Open Geosciences 8 (1):450-64. https://doi.org/10.1515/geo-2016-0029. 